\title{
Seasonal thermal energy storage in shallow geothermal systems: thermal equilibrium stage
}

\author{
Hossein Nowamooz ${ }^{\mathrm{a}}$, Saeid Nikoosokhan and Cyrille Chazallon ${ }^{1}$ \\ ${ }^{1}$ INSA de Strasbourg, Civil engineering department, 67084 Strasbourg Cedex, France
}

\begin{abstract}
This paper is dedicated to the study of seasonal heat storage in shallow geothermal installations in unsaturated soils for which hydrothermal properties such as degree of saturation and thermal conductivity vary with time throughout the profile. In the model, a semi-analytical model which estimates time-spatial thermal conductivity is coupled with a $2 \mathrm{D}$ cylindrical heat transfer modeling using finite difference method. The variation of temperature was obtained after 3 heating and cooling cycles for the different types of loads with maximum thermal load of $\mathrm{q}_{\max }=$ $15 \mathrm{~W} . \mathrm{m}^{-1}$ with variable angular frequency ( 8 months of heating and 4 months of cooling).and constant angular frequency ( 6 months of heating and 6 months of cooling) to estimate the necessary number of cycles to reach the thermal equilibrium stage. The results show that we approach a thermal equilibrium stage where the same variation of temperature can be observed in soils after several heating and cooling cycles. Based on these simulations, the necessary number of cycles can be related to the total applied energy on the system and the minimum number of cycles is for a system with the total applied energy of $1.9 q_{\max }$.
\end{abstract}

\section{INTRODUCTION}

Analysis on heat transfer in subsurface is important to size the BHE that optimum performance is achieved with minimum costs. To estimate thermal response of BHE accurately, knowledge of thermal properties of the ground is needed. The subsurface soil thermal properties such as thermal conductivity, and heat capacity play a vital role in heat transfer of BHE [1-2].

The entire process of heat extraction/deposition is a transient one, due to the weather-dependent ground surface boundary conditions and heating/cooling load. The soil water content in close vicinity to the BHE can be influenced by numerous factors, such as: soil structure, temperature gradient, water gradient and irrigation [3]. In particular, the temperature gradient in the soil surrounding the BHE plays an important role in the combined heat and water flow. Structural and textural properties of the same soil sample can vary considerably with seasonal climatic conditions. Therefore, thorough knowledge of the intricate nature of soils and transport phenomena related to coupled heat and water flow in the ground is essential to both the design and the operation of ground heat pump systems [4]. Due to the very complex character of the ground, the actual design of the BHE should be based on a detailed mathematical model of simultaneous heat and water flow in soils. The parameters influencing the soil thermal properties are essential for testing the BHE length and carrying out a parametric analysis, which is very useful for estimating the long-term effects of BHE operation on the surrounding ground. The results of laboratory testing of soil samples (soil texture, soil dry density, water content) should also be available prior to the evaluation of soil thermal properties.

A few papers dealing with the influence of soil types and moisture conditions on ground heat pump performance have been published in the last decade $[4$, 5]. Hailey et al. [6] analyzed the behavior of the thermal conductivity of soils adjacent to the BHE. It was found that soil water content was a dominant factor responsible for seasonal thermal conductivity variations. Drown and Braven [7] monitored for several seasons the effect of soil conditions and thermal conductivity on heat transfer in ground heat storage. Increase of the soil thermal conductivity by $0.17 \mathrm{~W} \cdot \mathrm{m}^{-1} \cdot \mathrm{K}^{-1}$ led to reduction of heat pump operating time by $1.3 \%$.

Moreover, there exists a lack of research on the investigation of the thermal response of BHE with regard to the time periodic thermal loads and its effects on the thermal equilibrium stage.

In this study, the simulation of seasonal heat storage in the Shallow Borehole Heat Exchangers (SBHE) installed in multilayered soil subsurface in Alsace region is performed. We perform a series of $2 \mathrm{D}$ numerical simulations to study the effect of time periodic thermal loads with variable angular frequency (8 months of heating and 4 months of cooling) and constant angular frequency (6 months of heating and 6 months of cooling) on the temperature variations around the SBHE in Alsace region. These simulations considered the variable thermal diffusivities of the different soil layers to estimate the

\footnotetext{
a Hossein.Nowamooz@insa-strasbourg.fr
} 
necessary number of cycles to reach the thermal equilibrium stage.

\section{FINITE DIFFERENCE METHOD}

Borehole Heat Exchanger (BHE) is considered as a geothermal system storage at shallow levels (less than $100 \mathrm{~m})$. Figure 1 shows a schematic geothermal system installed in a non-homogenous soil while the groundwater level varies with time and depth.

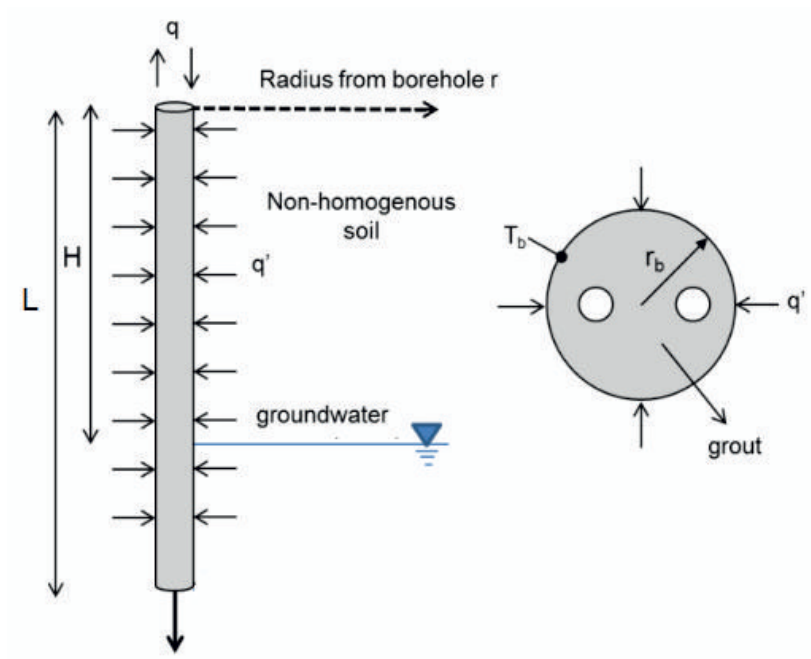

Figure 1. Schematic diagram of a shallow geothermal system installed in a non-homogenous soil with variable groundwater level.

Hydrothermal properties of the soil change with depth and time thus a 2D axisymmetric model is performed with finite difference method. The borehole is subjected to a heat flux q. We assume that such heat flux $\mathrm{q}$ is equal to the heat flux q' per unit length at the borehole radius.

The heat transfer problem is governed by the following partial differential equation in cylindrical coordinates:

$\frac{1}{r} \frac{\partial}{\partial r}\left(\alpha r \frac{\partial T}{\partial r}\right)+\frac{\partial}{\partial z}\left(\alpha \frac{\partial T}{\partial z}\right)=\frac{\partial T}{\partial t}$

where $\alpha$ is the thermal diffusivity, $\mathrm{T}$ is the temperature, $\mathrm{t}$ is the time and $\mathrm{z}$ is the depth.

The following equations are defined where $i$ is the counter of $\mathrm{r}$; $\mathrm{j}$ is the counter of $\mathrm{z}$; and $\mathrm{k}$ is the counter of $\mathrm{t}$.

$$
\begin{aligned}
& \frac{\partial^{2} T}{\partial r^{2}}=\frac{T_{i+1, j, k}-2 T_{i, j, k}+T_{i-1, j, k}}{d r^{2}} \\
& \frac{1}{r} \frac{\partial T}{\partial r}=\frac{T_{i+1, j, k}-T_{i-1, j, k}}{2 r r_{i} d r} \\
& \frac{\partial^{2} T}{\partial z^{2}}=\frac{T_{i, j+1, k}-2 T_{i, j, k}+T_{i, j-1, k}}{d z^{2}} \\
& \frac{\partial T}{\partial t}=\frac{T_{i, j, k+1}-T_{i, j, k}}{d t} \\
& \frac{\partial \alpha(z, t)}{\partial z} \frac{\partial T}{\partial z}=\frac{\alpha_{j+1, k}-\alpha_{j-1, k}}{2 d z} \frac{T_{i, j+1, k}-T_{i, j-1, k}}{2 d z}
\end{aligned}
$$

By replacing above equations 2 to 6 in Equation 1, the temperature $\mathrm{T}$ at time $\mathrm{k}+1$ computed in each iteration until the difference of temperature between two iteration becomes less than $10^{-4}$. Normally for the convergence we should have $\alpha \mathrm{dt} /\left(\mathrm{dr}^{2}+\mathrm{dz}^{2}\right)<0.5$.

For the boundary conditions, we consider that at $\mathrm{t}=0$, $\mathrm{T}=\mathrm{T}_{\mathrm{g} 0}$. No heat flux was also considered at large depth $(\mathrm{z}=\mathrm{L})$ :

$\left.\frac{\partial T}{\partial z}\right|_{z=L}=0$

Heat flux q' is considered to be calculated from the following equation:

$$
q^{\prime}\left(r=r_{b}, t\right)=-2 \pi r_{b} \lambda(z, t) \frac{\partial T}{\partial r}=q^{\prime}
$$

\section{ESTIMATION OF SOIL THERMAL PROPERTIES}

Nowamooz et al. [2] proposed a set of relationships for the fitting functions of thermal conductivity as well as thermal diffusivity adapted to different soils in the literature [8-10].

\section{a) Thermal conductivity}

We proposed the following equation for soil thermal conductivity with regard to the degree of saturation:

$$
\begin{aligned}
& \lambda=\left(\lambda_{\text {sat }}-\lambda_{\text {dry }}\right) \mathrm{K}_{\lambda}+\lambda_{\text {dry }} \\
& \lambda_{\text {sat }}=a x_{s}+b \gamma_{d} \\
& \lambda_{\text {dry }}=\mathrm{cx} \text { s }+d \gamma_{d} \\
& \mathrm{~K}_{\lambda}=\kappa S r /(1+(\kappa-1) S r) \\
& \kappa=e x_{s}+f
\end{aligned}
$$

where $\mathrm{Sr}$ is the degree of saturation $(-), \mathrm{x}_{\mathrm{s}}$ is the sand content $(-), \gamma_{\mathrm{d}}$ is the intial dry density $\left(\mathrm{kN} / \mathrm{m}^{-3}\right), \mathrm{K}_{\lambda}$ is the normalized thermal conductivity, $\lambda_{\text {dry }}$ and $\lambda_{\text {sat }}$ are the thermal conductivity of dry and saturated soils (Wm-1K1 ), $a$ and $b$ are fitted parameters for saturated thermal conductivity equal to $0.53 \mathrm{Wm}^{-1} \mathrm{~K}^{-1}$ and $0.1 \mathrm{Wm}^{2} \mathrm{~K}^{-}$ ${ }^{1} .(\mathrm{kN})^{-1}, \mathrm{c}$ and $\mathrm{d}$ are fitted parameters for unsaturated thermal conductivity equal to $0.087 \mathrm{Wm}^{-1} \mathrm{~K}^{-1}$ and 0.019 $\mathrm{Wm}^{2} \mathrm{~K}^{-1} .(\mathrm{kN})^{-1}, \kappa$ is dependent to the soil texture related to constant parameters e and f equal to 4.4 and 0.4 .

\section{b) Thermal diffusivity}

We proposed the following equation for soil thermal diffusivity with regard to the degree of saturation by considering the saturated thermal diffusivity $\left(\alpha_{\text {sat }}\right)$ and the dry thermal diffusivity $\left(\alpha_{\text {dry }}\right)$ :

$\alpha=\left(\alpha_{\text {sat }}-\alpha_{\text {dry }}\right)\left(\beta S r+(1-\beta) S r^{2}\right)+\alpha_{\text {dry }}$

where $\beta$ is a constant parameter taken equal to 4 .

Results from Abu-Hamdeh [8] and Ochsner et al. [10] show that there is no effect of initial dry density on the variation of thermal diffusivity. Therefore, we propose a linear relationship for saturated and dry thermal diffusivities $\left(\alpha_{\text {sat }}\right.$ and $\left.\alpha_{\text {dry }}\right)$ with respect to sand content $\mathrm{x}_{\mathrm{s}}$ : $\alpha_{\text {sat }}=\mathrm{ex}_{\mathrm{s}}+\mathrm{f}$

$\alpha_{\text {dry }}=\mathrm{gx}_{\mathrm{s}}+\mathrm{h}$

where e, $\mathrm{f}, \mathrm{g}$ and $\mathrm{h}$ are constant parameters of values 4.5 $\times 10^{-7} \mathrm{~m}^{2} \mathrm{~s}^{-1}, 3.5 \times 10^{-7} \mathrm{~m}^{2} \mathrm{~s}^{-1}, 2 \times 10^{-8} \mathrm{~m}^{2} \mathrm{~s}^{-1}$ and $1.8 \times$ $10^{-7} \mathrm{~m}^{2} \mathrm{~s}^{-1}$, respectively. 


\section{SIMULATION OF SHALLOW BOREHOLE HEAT EXCHANGER (SBHE) IN HANGENBIETEN (ALSACE REGION)}

In this section, we aim to study the thermal response of the multilayered subsurface soil around the SBHE installed in Hangenbieten of Alsace region. Using the geological and geotechnical characteristics of the multilayered subsurface soil, we first estimate thermal properties of the soil with our proposed theoretical approaches. Then, we perform a series of simulations to investigate the effect of variable time periodic thermal loads on the temperature variations around the SBHE.

\subsection{Geological, geotechnical, and thermal description of the multilayered subsurface}

The transfer of heat between the SBHE and the adjoining soil is governed primarily by heat conduction. Therefore, soil type is an important parameter which has effects on the heat transfer. Table 1 summarizes the geological and geotechnical description of the studied field in Hangenbieten such as the soil type, the sand content and the initial dry density [11]. $\mathrm{W}_{\text {sat }}$ is the saturated water content calculated by the initial dry density value $\left(\gamma_{\mathrm{d}}\right)$. The $\lambda_{\text {sat }}$ and $\alpha_{\text {sat }}$ of the different layers are calculated based on the equations 9 to 11 by considering their sand content $\mathrm{x}_{\mathrm{s}}$ and initial dry density $\gamma_{\mathrm{d}}$.

Soil at groundwater level in the field $(\mathrm{z}=8 \mathrm{~m})$ is considered to be in saturated state $(\mathrm{Sr}=100 \%)$. The variation of water content was reported in our previous publication (Nowamooz et al. 2015) during 3 years.

\begin{tabular}{|c|c|c|c|c|c|c|c|}
\hline & Soil type & Depth $(m)$ & $x_{5}(\%)$ & $\gamma_{d}\left(k N \cdot m^{-3}\right)$ & $\mathrm{w}_{\text {sat }}(\%)$ & $\lambda_{\text {sat }}\left(W \cdot K \cdot m^{-1}\right)$ & $\alpha_{\text {sat }}\left(m^{2} \cdot s^{-1}\right)$ \\
\hline & Vegetarian soil & $0-1$ & 65 & 13.5 & 36.3 & 1.69 & $6.78 \times 10^{-7}$ \\
\hline & Wind-blown silt & $1-4$ & 50 & 14 & 33.6 & 1.66 & $6.38 \times 10^{-7}$ \\
\hline & Loess & $4-8$ & 40 & 14.5 & 31.2 & 1.66 & $6.12 \times 10^{-7}$ \\
\hline & Loam & 8-9 & 30 & 14.5 & 31.2 & 1.61 & $5.9 \times 10^{-7}$ \\
\hline & Loess & $9-11$ & 40 & 15 & 28.8 & 1.71 & $6.09 \times 10^{-7}$ \\
\hline & Sit loam & $11-12$ & 30 & 15 & 28.8 & 1.66 & $5.88 \times 10^{-7}$ \\
\hline & Clay loam. & $12-13$ & 40 & 15 & 28.8. & 1.71 & $6.09 \times 10^{-7}$ \\
\hline & Loam & $13-16$ & 25 & 15,5 & 26.7 & 1.68 & $5.76 \times 10^{-7}$ \\
\hline & Sandy clay loam & $16-19$ & 30 & 16 & 24.7 & 1.76 & $5.84 \times 10^{-7}$ \\
\hline & Sandy Loam & $19-20$ & 80 & 16 & 24.7 & 2.02 & $6.84 \times 10^{-7}$ \\
\hline
\end{tabular}

Table 1. Profile of the multilayered subsurface in Hangenbieten (Alsace region), geological data are adapted from BRGM geological map.

\subsection{Thermal boundary conditions}

In the numerical model, the following boundary conditions were applied:
- At the surface of soil, temperature variations changes with time $\left(\mathrm{T}_{\mathrm{s}}\right)$. We have also the temperature variation during the period of 3 years at surface $(\mathrm{z}=$ $0)$.

- At large depth, there is no heat flux and soil temperature is considered as the same as the average temperature value of the ground $\left(\mathrm{T}_{\mathrm{g} 0}\right)$ at initial time $\mathrm{t}$ $=0$.

- At the interface between two layers $m$ and $m+1$, the continuity of temperature as well as the continuity of the heat flux was also considered.

- At the borehole radius, heat flux $\mathrm{q}_{0}$ varies with the variable thermal conductivity (see Eq. 8).

\subsection{Thermal equilibrium stage}

For the simulation, we apply 3 successive heating and cooling cycles of thermal loads $q(t)$ on the borehole installed in Hangenbieten with the height (L) of $20 \mathrm{~m}$, the radius $\left(\mathrm{r}_{\mathrm{b}}\right)$ of $5 \mathrm{~cm}$, and water table level $(\mathrm{H})$ of $8 \mathrm{~m}$.

Thermal loads $q(t)$ initially used for this site correspond to the same existing period of heating and cooling in Alsace region, i.e., 8 months of heating and 4 months of cooling. Three types of time periodic heat loads, each with variable angular frequency in a period of 1 year, are studied as presented in Figure 2: the first type represents 8 months of heating and 4 months of cooling with $\mathrm{q}_{\min }=-\mathrm{q}_{\max }$; the second type represents 8 months of heating and 4 months of cooling with $\mathrm{q}_{\min }=-\mathrm{q}_{\max } / 3$; the third one corresponds to no cooling load during summer $\left(\mathrm{q}_{\min }=0\right)$. Table 2 presents the loads $\mathrm{q}_{1}, \mathrm{q}_{2}$, and $\mathrm{q}_{3}$ with $\mathrm{q}_{\max }=15 \mathrm{~W} \cdot \mathrm{m}^{-1}$.

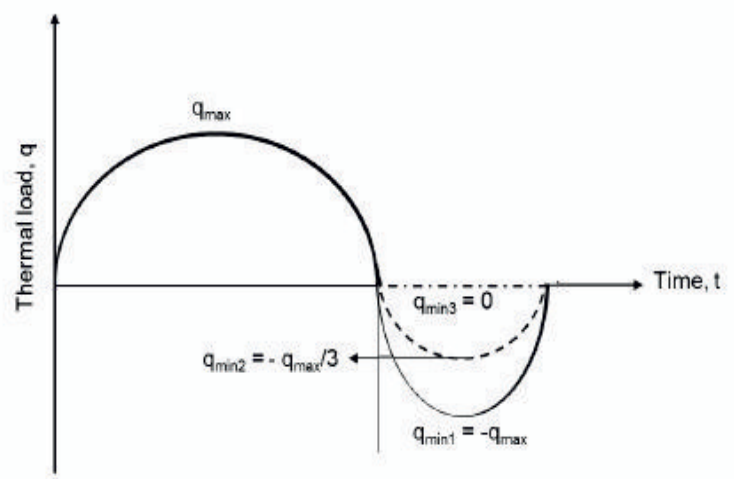

Figure 2. Schematic representation of time-periodic thermal loads with variable angular frequency: i) $q_{\min }=-q_{\max }$, ii) $q_{\min }=$ $\mathrm{q}_{\max } / 3$, iii) $\mathrm{q}_{\min }=0$.

In order to better estimate the number of cycles necessary for the thermal equilibrium stage in our calculations, we take also into account the effect of load angular frequency. For this reason, three additional types of time periodic heat loads with $\mathrm{q}_{\max }=15$ during 6 months of heating and 6 months of cooling (constant angular frequency) are studied: the first type represents a fully compensating load $\mathrm{q}_{7}$ with $\mathrm{q}_{\min }=-\mathrm{q}_{\max }$; the second type represents a partially compensating load $\mathrm{q}_{8}$ with $\mathrm{q}_{\min }$ 
$=-\mathrm{q}_{\max } / 3$; the third kind corresponds to no cooling load $\mathrm{q}_{9}$ during summer with $\mathrm{q}_{\min }=0$ (see Figure 3 and Table 2).

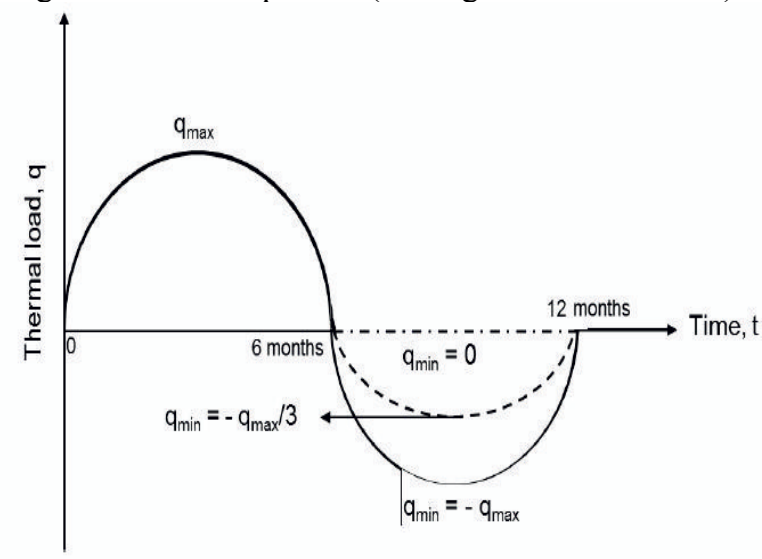

Figure 3. Schematic representation of time-periodic thermal loads with constant angular frequency: i) $q_{\min }=-q_{\max }$, ii) $q_{\min }=-$ $\mathrm{q}_{\max } / 3$, iii) $\mathrm{q}_{\min }=0$.

Table 2. Different thermal loads with constant and variable angular frequency.

\begin{tabular}{|c|c|c|c|}
\hline Thermal load $q(\mathrm{~W} / \mathrm{m})$ & Angular frequency $\oplus(\mathrm{rad} / \mathrm{t})$ & $q_{\max }(W / m)$ & $q_{\min }(W / m)$ \\
\hline$q_{1}$ & \multirow{3}{*}{$\begin{array}{l}\text { Variable frequency } \\
\omega_{1}=\frac{3 \pi / 2}{12 \text { months }} \\
\omega_{2}=\frac{3 \pi}{12 \text { months }}\end{array}$} & 15 & -15 \\
\hline $\mathrm{q}_{2}$ & & 15 & -5 \\
\hline$q_{3}$ & & 15 & 0 \\
\hline$q_{7}$ & \multirow{3}{*}{$\begin{array}{l}\text { Constant frequency } \\
\omega_{1}=\omega_{2}=\frac{2 \pi}{12 \text { months }}\end{array}$} & 15 & -15 \\
\hline$q_{8}$ & & 15 & -5 \\
\hline$q_{9}$ & & 15 & 0 \\
\hline
\end{tabular}

Figure 4 shows the variation of temperature for the thermal loads $\left(\mathrm{q}_{1}, \mathrm{q}_{2}, \mathrm{q}_{3}, \mathrm{q}_{7}, \mathrm{q}_{8}\right.$, and $\left.\mathrm{q}_{9}\right)$ with radius at the depth of $2.5 \mathrm{~m}$ and with depth at the radius of $0.34 \mathrm{~m}$ (close to the borehole) after 1 year, after 2 years, and after 3 years.

We can observe that a thermal equilibrium stage can be reached where the soil presents the same temperatures after several heating and cooling cycles. Moreover, thermal equilibrium stage can be reached more rapidly for the thermal load $\mathrm{q}_{1}$ where $\mathrm{q}_{\min }=-\mathrm{q}_{\max }$ compared with the other two types of thermal load $\mathrm{q}_{2}$ and $\mathrm{q}_{3}$. For both thermal loads $\mathrm{q}_{2}$ and $\mathrm{q}_{3}$, a decrease of temperature can be observed after 3 years. Further calculations show that 2 or 3 additional cycles are sufficient for the thermal loads $q_{2}$ and $\mathrm{q}_{3}$ to reach the thermal equilibrium stage.

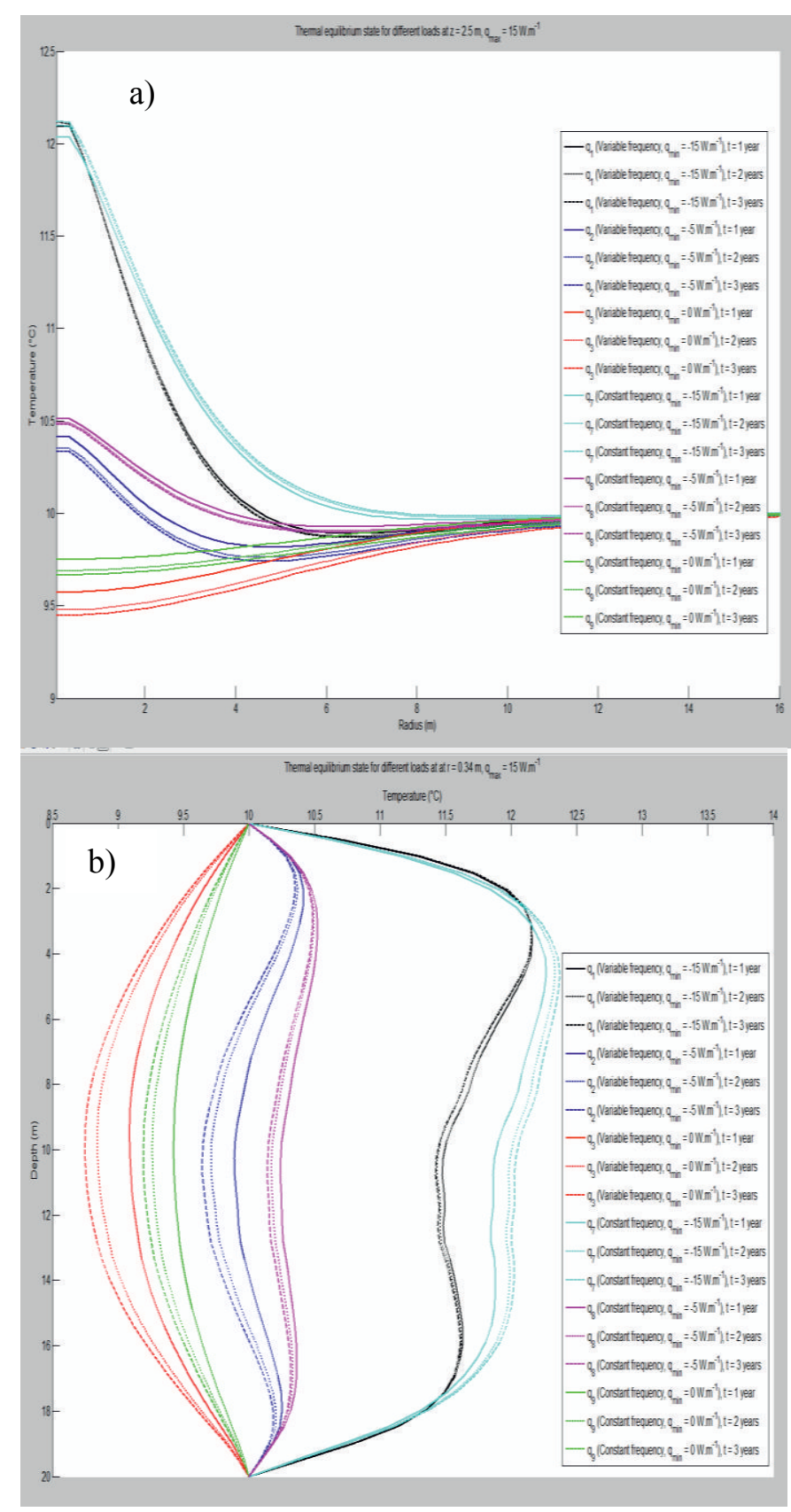

Figure 4. Comparison of temperature variations between variable and constant angular frequency thermal loads after 3 heating and cooling cycles: a) with radius at the depth of $2.5 \mathrm{~m}$ and b) with depth at the radius of 0.34 for the six thermal loads presented in Table 2.

We can also observe in Figure 4 that the thermal load $\mathrm{q}_{8}$ requires less number of cycles to reach thermal equilibrium stage compared with other thermal loads $\mathrm{q}_{7}$ and $\mathrm{q}_{9}$. Moreover, an increase of temperature after 3 years is observed for $\mathrm{q}_{7}$ while it decreases for $\mathrm{q}_{9}$.

The following observations can be made on the difference of temperature variations between first and third year:

- In the case of $\mathrm{q}_{1}$ and $\mathrm{q}_{7}$ with $\mathrm{q}_{\min }=-\mathrm{q}_{\max }$, the difference for variable angular frequency $\left(\mathrm{q}_{1}\right)$ is almost the same between first and third year while it decreases for the constant angular frequency $\left(\mathrm{q}_{7}\right)$. 
- In the case of $\mathrm{q}_{2}$ and $\mathrm{q}_{8}$ with $\mathrm{q}_{\min }=-\mathrm{q}_{\max } / 3$, the difference for constant angular frequency $\left(\mathrm{q}_{8}\right)$ is almost the same while it decreases for the variable angular frequency $\left(\mathrm{q}_{2}\right)$.

- In the case of $\mathrm{q}_{3}$ and $\mathrm{q}_{9}$ with $\mathrm{q}_{\text {min }}=0$, the difference for both constant and variable frequencies decreases during this period.

In order to interpret our observations, we define the total applied energy $\mathrm{E}$ of the thermal load with the unity of W.month $/ \mathrm{m}$, calculated by the following equation:

$$
E=\int_{0}^{12 \text { months }} q(t) d t
$$

Figure 5 shows the variation of the maximum temperature difference between first and third year, $\Delta \mathrm{T}$, with respect to the total applied energy E. We can observe that the maximum difference of temperature between first and third year becomes zero for a system with the total applied energy $\mathrm{E}=1.9 \mathrm{q}_{\max }$.

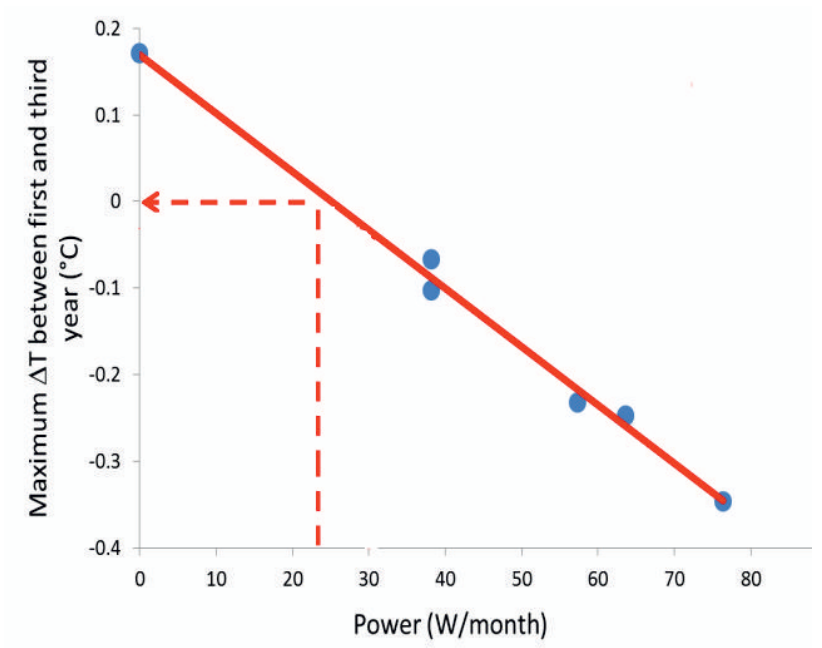

Figure 5. Variation of the maximum temperature difference between first and third year $(\Delta \mathrm{T})$ with respect to the total applied energy $\mathrm{E}$ (linear fit).

\section{CONCLUSION}

This study deals with a finite difference modeling of heat transfer in unsaturated multilayered soil while hydrothermal properties of soil differ in each layer.

A profile of thermal diffusivity within time is assigned to each node in finite difference formulation. The numerical model requires easily accessible input parameters such as water content, dry density, and sand content of the soil profile. It is coupled with the reliable theoretical approaches which estimate thermal properties of soil such as thermal conductivity and thermal diffusivity.

The variation of temperature was obtained after 3 years for the three types of loads $\mathrm{q}_{\min }=-\mathrm{q}_{\max }, \mathrm{q}_{\min }=$ $\mathrm{q}_{\max } / 3$, and $\mathrm{q}_{\min }=0$ with maximum thermal load of $\mathrm{q}_{\max }=$ $15 \mathrm{~W} . \mathrm{m}^{-1}$ with variable angular frequency $(8 \mathrm{months}$ of heating and 4 months of cooling).and constant angular frequency (6 months of heating and 6 months of cooling). The results show that we approach a thermal equilibrium stage where the same variation of temperature can be observed in soils after several heating and cooling cycles.

Globally, the necessary cycles to reach the thermal equilibrium stage is dependent on several factors such as the angular frequency of thermal load, the type of the thermal load, the intensity of the thermal load, and the climate conditions of the region. Based on our investigations, we propose that the total applied energy on the system can be a good alternative to estimate the required number of cycles to reach the thermal equilibrium stage.

In this study, only heat transfer was considered. In our future studies, the coupled heat and mass transfer constitutive relationships will be taken into account.

\section{ACKNOWLEDGEMENT}

This work was funded by the European Commission Initiative INTERREG IV A, Upper Rhine program (project B20, TEM3).

\section{REFERENCES}

1. Nikoosokhan S., Nowamooz H., Chazallon C., 2015. Temperature variations in unfrozen soils with variable hydrothermal properties, European Journal of Soil Science, 66, 378-388.

2. Nowamooz H., Nikoo-Sokhan S., Lin J., Chazallon C., 2015. Finite difference modeling of heat distribution in multilayer soils with time-spatial hydrothermal properties, International Journal of Renewable Energy, 76, 7-15.

3. Krarti, M., Claridge, D.E. \& Kreider, J.F., 1995. Analytical model to predict nonhomogeneous soil temperature variation, Transacations of ASME. 117.

4. Leong, W., Tarnawski, R. \& Aittomaki, A., 1998. Effect of soil type and moisture content on ground heat pump performance, International Journal of Refrigeration. 21, 595-606.

5. Song, Y. Yao, Y. \& Na, W. 2006. Impacts of soil and pipe thermal conductivity on performance of horizontal pipe in a ground-source heat pump, Proceedings of the Sixth International Conference for Enhanced Building Operations, Shenzhen, China.

6. Hailey, S.M., Kast, T.P. \& Drown, D.C., 1990. Thermal conductivity and soil conditions: heat transfer effects on ground source heat pumps, Proceedings of the 16th Annual Conference of Solar Energy Society of Canada, Halifax, Nova Scotia.

7. D. Drown, K \& Den Braven, 1992. Effect of soil conditions and thermal conductivity on heat transfer in ground source heat pumps, Proceedings of the ASME JSES KSES International Solar Energy Conference, Maui, Hawaii.

8. Abu-Hamdeh N.H, 2003. Thermal Properties of Soils as affected by Density and Water Content, Biosystems Engineering. 86, 97-102.

9. Lu, S., Ren, T., Gong, Y. \& Horton, R., 2007. An improved model for predicting soil thermal conductivity from water content at room 
temperature, Soil Science Society of America Journal. 71, 8-14.

10. Ochsner, T.E., and Horton, R., \& Ren, T. 2001. A New Perspective on Soil Thermal Properties, Soil Science Society of America Journal. 65, 1641-1647.
11. BRGM, 2000. report for geological map, Editions BRGM. 